\title{
Poéticas de la ciudad: chantier a cielo abierto
}

\author{
Poetics of the City: an Open-Air Chantier \\ Cristina RodríGuez MARCIEL \\ UNED \\ crmarciel@fsof.uned.es
}

Recibido: 05/07/2013

Aceptado: 30/05/2014

\section{Resumen}

Sin constituir un "concepto" de la filosofía de Jean-Luc Nancy, el término francés "chantier", de difícil traducción al español, nos sirve en este artículo para dar cuenta del tratamiento que Nancy le ha dado a la ciudad en los textos con los que, durante más de veinte años, ha ido delimitado sus rasgos específicos y sus caracteres propios. Más allá de su unidad conceptual, la ciudad se revela como la pluralidad de los "modos de hacer y de producir" (poéticas) que le permiten a Nancy exceder los compartimentos disciplinarios. Con muy escasas ocurrencias en su trabajo, en este artículo pretendemos demostrar que "chantier" es un término privilegiado que da cuenta, paradójicamente, de cómo las obras en construcción (traducción provisional del término) desestabilizan el paradigma arquitectural "constructivista" con que se ha configurado el esquema completo de representaciones del pensamiento occidental.

Palabras clave: Jean-Luc Nancy, poéticas, ciudad, construcción, deconstrucción, struction.

\begin{abstract}
Without forming a "concept" of the philosophy of Jean-Luc Nancy, the French term "chantier", which is difficult to translate into Spanish, is used in this paper to account for the treatment that Nancy has given to the city in the texts with which he has been defining its specific features and particular characteristics for over twenty years. Beyond its conceptual unity, the city is revealed as the plurality of the "ways of making and producing" (poetics) that allow Nancy to transcend disciplinary compartments. With very few occurrences in his work, in this paper we show that "chantier" is a privileged term that, paradoxically, accounts for how work under construction (provisional translation of the term) destabilise the "constructivist" architectural paradigm with which the complete scheme of representations of Western thought have been configured.
\end{abstract}


Keywords: Jean-Luc Nancy, poetics, city, construction, deconstruction, struction.

Jean-Luc Nancy lleva el nombre de una ciudad. Solamente es una anécdota. Pero la anécdota es hermosa (desconocida, que yo sepa) y merece ser contada. Tuvo lugar en Saumur en el siglo XIX. Una mujer llevó al registro civil a un niño que había encontrado, sin padre conocido, por supuesto. ¿Qué nombre darle? Resultó que el empleado del registro civil era originario de una ciudad del este de Francia. Tomaron una decisión: este niño se llamará Nancy. Fue antepasado de Jean-Luc.

Benoît Goetz, Les villes de Nancy

El prurito de la eventual tarea de traductora en que a veces me embarco, me lleva, en primer lugar, a pedir disculpas al lector por haber dejado circular en mi título la palabra francesa chantier. Las disculpas, obviamente, no tienen su origen en el hecho de haber permitido que una palabra extranjera se abra paso entre las mías ya que, por lo demás, esa contaminación o contigüidad ocurre constantemente entre las lenguas, unas veces de manera superflua y otras de manera muy necesaria; las disculpas vienen impuestas porque cuando ese gesto tiene lugar en la traducción, como es el caso, puesto que la palabra "chantier" me ha llegado de los textos originales de Nancy, tomar la decisión de suspender la traducción, siempre equivale a constatar un fracaso, una impotencia o una imposibilidad del traductor en particular o de la propia traducción en general. Sin embargo, bien sabemos que, precisamente, esa "excepción de lo intraducible"1 constituye la ley de la traducción. Sin esta "excepción que hace la ley, puesto que expone e impone la irreductibilidad del idioma", ya no habría que traducir, pero tampoco habría lenguas. Un estado de excepción está en el origen de la soberanía e igual de soberanos se muestran, en este caso, tanto la insurrecta lengua que se declara intraducible, como el traductor que decide soberanamente dejar la palabra en el idioma original, resguardada en su lengua de partida, inmovilizada en su venida sin permitir que su sentido pase de una lengua a otra. De ese modo, el sentido se sustrae porque no llega a significarse de un idioma a otro y, sin embargo, esa insignificabilidad residual de la palabra está circulando ya en la lengua de llegada. El soberano deroga así el orden establecido de la comunicación y de la significación, pero abre en ese orden una zona de insinuación o de sugerencia, un corto intervalo de invitación, de seducción o extravío que señala hacia el sentido último del sentido que no es otro que: "Aquí, soberanamente, el sentido se excluye del

${ }^{1}$ J.-L. Nancy, "D’un Wink divin”, en La Déclosion (Déconstruction du christianisme, 1), París, Galilée, 2005, p.158. 
sentido"2. En ese gesto siempre hay implícita una declaración de impropiedad o de incapacidad con respecto al sentido significado: no he encontrado o acaso no quise encontrar una solución por "equivalencia", como suele decirse, ni una perífrasis, ni una analogía, ni cualquier otro recurso o procedimiento de traslación o traspaso. Ahora bien, y en todo caso, ese gesto soberano siempre abre el sentido a un sentido diferente, y si se evade con respecto a la significación, no deja sin embargo de dirigirse a nosotros como una llamada, ni nosotros dejamos de recibirlo como una desconcertante extrañeza. Habrá que traducir, sí, pero no ahora, por el momento dejaremos la palabra en espera de su sentido y, así, en chantier, la palabra "se suspende entre la decepción y la espera" 3 . Podemos esperar su interpretación, por supuesto, y en esa espera siempre hay una moción, una movilización, un movimiento, y la motilidad de la espera importa más que su interpretación final. Y es que, como ha escrito Nancy, "todo es dado a cada lengua, pero en absoluto de la misma manera"4.

A quienes no hablen francés, les contaré que si la palabra "chantier" se subleva y se le declara en rebeldía a la traducción es porque en español llamamos muy generalmente "obra" a lo que con gran precisión el francés llama "chantier". Me resultará muy fácil explicarles lo que es un chantier si, por ejemplo, les remito a una magnífica película estrenada en 2001, dirigida por José Luis Guerín y cuyo título es o, mejor, está En construcción. El documental de Guerín tiene como escenario la rehabilitación del barrio del Raval en Barcelona. Si a esa película hubiera habido que ponerle un título en francés habría sido Chantier. La obra en construcción no es todavía la obra en el sentido de la cosa hecha y producida por un agente, sino la obra que no está acabada porque precisamente sólo es obra en construcción, obra que se define por su proceso, obra que se refiere a sí misma en su curso y en su transformación, y no en su culminación, en su fin o acabamiento. La obra debe anticipar y preformar su resultado, obviamente, pero éste procederá de la transformación progresiva del propio chantier cuyo destino será su metamorfosis en obra acabada, pero que de ese modo será ya otra cosa. Por lo demás, en el chantier no sólo se da la acción o actividad que producirá el edificio o la casa. El chantier no es sólo el proceso de construcción de la casa, el proceso de la oikodomiké que, según Aristóteles, es un arte y un modo de ser racional para la producción, es decir, para la poietiké5, la construcción de la mo-

\footnotetext{
${ }^{2}$ Ibidem, p. 157.

${ }^{3}$ Ibidem, p. 158.

${ }^{4}$ J.-L. Nancy, Les Muses, París, Galilée, 2004, p. 183.

${ }^{5}$ Aristóteles, Ética nicomáquea, 1140a. "El arte. Entre lo que puede ser de otra manera está el ob-

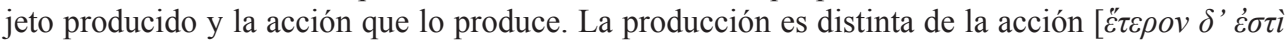

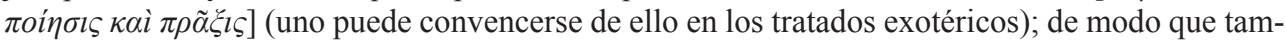
bién el modo de ser racional práctico es distinto del modo de ser racional productivo. Por ello, ambas se excluyen recíprocamente, porque ni la acción es producción, ni la producción es acción. Ahora bien, puesto que la construcción es un arte y es un modo de ser racional para la produc-
} 
rada y de la habitación no son las únicas producciones del chantier; no sólo se trata, como decía Heidegger, "[d]el construir como habitar [que] se despliega en el construir que cuida, es decir, que cuida el crecimiento... y en el construir que levanta edificios", sino que también, y por ejemplo, chantier son las obras del viaje, del tráfico y la travesía, de las redes viarias y del transporte urbano, ya sea subterráneo o de superficie: en chantier la ciudad despliega en sí misma la forma de un transporte que la refiere a sí misma, que no tiene otro fin que la propia remisión. Acaso, precisamente por eso, las obras de la redes viarias sean las más propias de la ciudad, las más urbanas y las más urbanitas, porque, por una parte, son las que ponen en evidencia con mayor acuidad la íntima y esencial relación que el chantier mantiene con la ciudad, mostrando como "la ciudad ha comenzado por las obras y no puede vivir sino gracias a ellas e incluso en ellas", y porque, por otra parte, desplegando esa red que no hace sino referirla a sí misma, la ciudad tiene la ocasión de mostrar su carácter de sujeto y no de objeto. El chantier hace vivir a la ciudad y le arrebata el estatuto de objeto. En chantier "la ciudad se subjetiva" porque "como un sujeto se refiere esencialmente a sí y, de manera muy lógica, se extravía en sí hasta ya no poder distinguirse: confundirse consigo constituye a la vez el colmo de la identidad y el del extravío" . De ese modo, el chantier exhibe la contradicción de una dirección sin orientación final, esto es, una mera circulación, una deambulación y un tránsito. Obras son también las de las "conducciones", el conjunto de los canales o tubos que dan paso y salida a la circulación, obras con las que es preciso horadar la tierra, abrir el asfalto de la calzada y los adoquines de las aceras procediendo de manera casi quirúrgica para que el chantier se transforme a partir de ese momento en una operación a corazón abierto. El chantier es entonces el intruso ${ }^{9}$ en la ciudad. Por eso ha podido escribir Nancy que en la ciudad coexisten dos mundos distintos y con dos lógicas heterogéneas: por una parte, la ciudad está "en funciones", esto es, en el ejercicio propio de su cargo y de sus tareas, de sus afanes, de sus trabajos y de sus días y, por otra parte, hay una ciu-

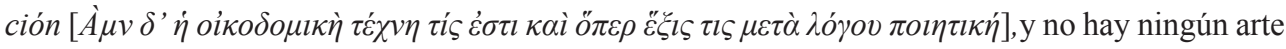
que no sea un modo de ser para la producción, ni modo de ser de esta clase que no sea un arte, serán lo mismo el arte y el modo de ser productivo acompañado de la razón verdadera. Todo arte versa sobre la génesis, y practicar un arte es considerar cómo puede producirse algo de lo que es susceptible tanto de ser como de no ser y cuyo principio está en quien lo produce y no en lo producido". (Las cursivas son mías).

${ }^{6}$ M. Heidegger, "Construir, habitar, pensar", en Conferencias y artículos, traducción de E. Barjau, Barcelona, Serbal, 2001, p. 143.

7 J.-L. Nancy, Trafic/Déclic, coll. Carnets, París, La Phocide, 2010, p. 19.

${ }^{8}$ J.-L. Nancy, "Images de la ville", en La Ville au loin, París, La Phocide, 2011, p. 61.

${ }^{9}$ A partir de su experiencia vital de padecer un trasplante de corazón, Nancy ha elaborado con el término "intruso" algo así como un "concepto" de su pensamiento. $C f$. J.-L. Nancy, L'intrus, París, Galilée, 2000. 
dad que experimenta la intrusión y la extrusión, la ciudad que está, dice, "pariendo o en trasplante": se hacen tajos, incisiones, zanjas y se encastran conductos, canales, tuberías con cableados eléctricos, fibras ópticas, conductos de gas, de agua, hasta formar un "ductus proliferante y reticular" en un telurismo que ya no es "ctónico" porque los dioses del subsuelo, en una conocida fórmula nancyana, también "se han retirado" ${ }^{10}$. Acaso quede, habitando el subsuelo, una despistada afrodita subterránea, salida del Peán ${ }^{11}$ que Nancy le dedica, para invertir el sentido de lo profundo de manera que "la profundidad se eleve a la superficie multiplicada" y para que "lo divino" pueda consistir en "que no haya nada escondido, nada abstruso ni secreto". Las obras despliegan de ese modo una inmensa fenomenalidad que se ofrece a la vista, que es "visibilidad pero no transparencia" porque, muy al contrario: el chantier permite "que se desplace la oscuridad que la ciudad es en sí misma" y deja que se ponga en evidencia algo invisible que nos apremia a mirar sin consentir que la mirada pueda apropiarse de lo que mira. Así es como la mirada de Nancy cuida de lo que mira. Su mirada sobre la ciudad cuida de la ciudad, sustituyendo a las visiones, las previsiones o los proyectos que sólo desean dominarla ${ }^{12}$.

Esto que les he descrito, acaso de manera demasiado prolija, es un chantier y quizás, en este momento, ante el lector se amontonan y se apiñan (no olviden esos dos verbos porque volverán un poco más adelante) imágenes de esa existencia múltiple, móvil pero también instantánea del chantier: "Si la ciudad, con frecuencia, germina a partir de un fuerte o de una capilla", de un centro, en definitiva, no es ese centro el que le es "consustancial". La ciudad tiene una naturaleza muy diferente y, según Nancy, se da en destellos, en fogonazos, en esquirlas, en pedazos, "en fragmentos que únicamente se reúnen mediante una unidad flotante, nominal y simbólica, siempre mal identificable en lo real de sus trazados, de sus tráficos y de sus removimientos" ${ }^{\prime 13}$. A esa captación, de algún modo siempre fotográfica, de la ciudad en chantier, se añade una "impresión", sentida a veces como una presión y como una opresión. Instantáneas, imágenes en chantier: excavadoras, dragas, perforadoras, martillos neumáticos, piquetas, llanas, vigas, tenazas, brocas, taladros, barrenas, grúas, buldóceres, hormigoneras... Entre esas imágenes que le son propias están también unos modos de

\footnotetext{
${ }^{10}$ Esta expresión ha dado título a uno de sus libros, sin embargo, puede rastrearse en toda su obra, en especial, en los textos dedicados a lo que ha llamado "la deconstrucción del cristianismo". Véase J.-L. Nancy, "Un jour, les dieux se retirent...", Bourdeaux, William Blake \& Co., 2001.

${ }^{11}$ J.-L. Nancy, La naissance des seins suivi de Péan pour Aphrodite, París, Galilée, 2006.

12 "“Mirar" [regarder] equivale en primer lugar a guardar [garder], warden o warten, vigilar, estar al cuidado y tener cuidado. Esmerarse e inquietarse. Al mirar, yo velo, cuido y (me) guardo: estoy en relación con el mundo, no con el objeto. Y es así como "soy": en el ver, yo veo, por razón de óptica, en la mirada soy puesto en juego. No puedo mirar sin que eso me mire y me concierna [ça me regarde]". (J.-L. Nancy, Le regard du portrait, París, Galilée, pp. 74-75).

${ }^{13}$ J.-L. Nancy, Trafic/Déclic, op. cit., pp. 9-10.
} 
delimitación del espacio muy característicos: el chantier señala sus contornos y sus fronteras de manera muy endeble e inestable, se resguarda sólo provisionalmente rodeándose de estrechas empalizadas de metal ondulado, de pretiles mudables a media altura, de ligeros vallados móviles que suscitan en nosotros la misma pregunta formulada en la celebérrima muralla china de Kafka: “¿qué defensa puede ofrecer una muralla discontinua?". El chantier se tapia y se circunda al tiempo que se destripa y se expone. Posee su propio lenguaje de signos y códigos: "Prohibido el paso a toda persona ajena a la obra", "atención salida de vehículos", "es obligatorio usar casco", "peligro carga suspendida", "desvío provisional", "riesgo eléctrico"... Y tiene su propia población nómada. Está ocupado sin permanencia por aquellos que, como decía Lacoue-Labarthe, "pertenecen al recinto indiferenciado del chantier [...], que no los miremos nunca no significa que no sean visibles. Todo, por el contrario, está hecho para que se los vea"14: ropa corriente de trabajo de colores vivos acidificados, contrastados y vibrantes, con grandes franjas fluorescentes y cascos de protección también coloreados: "su visibilidad es absoluta". Cromatismo chillón como chillona es la banda sonora de la obra: decibelios imposibles de martillos mecánicos, cascotes que caen en los contenedores, pitidos estridentes de los avisadores de los vehículos, chirridos de poleas...

Una aclaración última con respecto al chantier "a cielo abierto" del título. Ese cielo abierto no se refiere al calum, morada de Dios, de los ángeles y de los justos, ni al cielo decorativo o expresivo de los pintores, ni a la esfera aparentemente azul y diáfana que rodea la Tierra. Ni al cielo de la expresión castellana que implica que ver un cielo abierto consiste en que se le presenta a alguien la ocasión o la coyuntura favorable para salir de un apuro o conseguir un deseo. El chantier a cielo abierto es un cielo sin dioses y sin revelación porque, de modo mucho más prosaico -o quizás más poietikós puesto que poiesis es, precisamente, "construcción"-, una "obra a cielo abierto" 15 es un término que describe un tipo de obra civil que se realiza sin techo ni cobertura alguna; es el concepto opuesto a "obra subterránea". Enseguida podré mostrar que todas estas exhaustivas y prolijas precisiones no son gratuitas ni meramente anecdóticas. No se puede afirmar en absoluto que Nancy haya hecho del chantier algo así como un concepto de su pensamiento y, sin embargo, y es la tesis que quiero defender aquí, el término puede ser considerado netamente descriptivo de la estrategia de trabajo que él pone en marcha cuando se enfrenta con cada uno de los que Derrida llamó sus "grandes conceptos" ${ }^{16}$. La ciudad será entonces sólo un ejemplo, un

\footnotetext{
${ }^{14} \mathrm{Ph}$. Lacoue-Labarthe, "En atención", traducción de A. del Río Herrmann, en revista Desobra 1, 2002, pp. 137-152, aquí 137.

${ }^{15}$ M. León, Diccionario del tren, Madrid, Díaz de Santos, 1999, p. 341.

${ }^{16}$ J. Derrida \& J.-L. Nancy, "Responsabilité-du sens à venir" en Sens en tous sens. Autour des travaux de Jean-Luc Nancy, París, Galilée, 2004, p. 167.
} 
ejemplo privilegiado, por supuesto, en la medida en que el exemplum, como Nancy nos recuerda, consiste en retirar algo de su condición común e indistinta, será un ejemplo que nos ayudará a ver como el pensamiento de Nancy es un pensamiento indiscernible de su praxis. Un ejemplo de la estrategia, del gesto, del estilo o del trazado que, en general, Nancy, reclama para el pensamiento.

En solo una ocasión, entre los muchos textos que Jean-Luc Nancy le ha dedicado a la ciudad, un texto de 2004, titulado "Trafic/Déclic", y que está traducido en español como "Tráfico/cliqueo"17, tiene la originalidad de poner el acento, como antes he adelantado, en la esencial relación que el chantier mantiene con la ciudad. Hasta donde yo sé, sólo en este texto el chantier es explícitamente tematizado por Nancy como respuesta, además, a una circunstancia muy concreta vinculada con la implantación de una nueva línea de tranvía en Estrasburgo. El fotógrafo Nicolas Faure realizó una centena de fotografías de ese chantier à ciel ouvert y se invitó a Lacoue-Labarthe y a Nancy a tomarlas como motivo para la redacción de dos textos. "Trafic/Déclic" fue la aportación de Nancy a ese proyecto que articulaba un pensamiento de la ciudad con un pensamiento de la fotografía desplegados a través del singular punto de vista de las obras. El texto de Nancy no es en absoluto un ditirambo laudatorio, no quiso tratar de captar y exponer una supuesta belleza de las obras ni una presunta "poesía" del chantier, aunque sea el chantier, precisamente, el que me haya permitido referirme en el título a unas poéticas de la ciudad, esto es, poéticas como los modos múltiples y diferentes de hacer y de producir del chantier en la ciudad, porque eso son las poéticas: modos de hacer y de producir, de construir, que siempre son plurales además porque, como diría Aristóteles, lo que es objeto de la producción está entre las cosas que siempre pueden ser de otra manera y de muchas maneras. Las producciones del chantier, las obras, como ha escrito Nancy, "carecen a menudo de urbanidad, son desagradables, agobiantes de ruidos y de polvo, ponen trabas al paso y al acceso, llenando de baches los trayectos, cambiando los hábitos, separando los barrios, sin hacer barrio" y, sin embargo, con una singular belleza que no puede obviarse, Nancy apunta, como hemos adelantado, a la mencionada coesencialidad de las obras y de la ciudad hasta el punto de afirmar que las obras intensifican el ser-ciudad de la ciudad y no puede ser más gráfico cuando dice: "El chantier en efecto multiplica el ser-ciudad de la ciudad y de alguna manera lo exalta al mismo tiempo que varía su disposición: como el perfume de una flor se desprende, se exhala por el arrugamiento, por el aplastamiento de sus fibras entre unos dedos apretados [...]. La ciudad ha comenzado por las obras y no puede vivir sino gracias a ellas e incluso en ellas. La ciudad se construye deconstruyéndose. Al deconstruirse se desensambla para

${ }^{17}$ J.-L. Nancy, "Tráfico/Cliqueo", traducción de I. Herrera Baquero, en Desobra 1, 2002, pp. 5-19. Cito las versiones francesa y española de este texto porque los contenidos de ambos títulos no son coincidentes. 
ensamblarse de otro modo, para ensamblar una incesante alteridad siempre transformable, siempre continuada, siempre renovada" 18 .

Antes de conocer la existencia de este escrito de Nancy, y de nuevo hasta donde yo sé, el término chantier había tenido tres únicas ocurrencias en su trabajo, alejadas en todo caso de los textos que durante más de veinte años Nancy le ha dedicado a la ciudad $^{19}$. Tres ocurrencias que, no obstante, impedían que el término hubiera podido pasarme desapercibido. No me pasó desapercibido supongo que, de nuevo, por el hecho de que leo a Nancy en su lengua, pero buscando siempre para cada palabra suya lo que Flaubert llamaba le mot juste para traerlo a la mía. Y me encontré, ya lo he indicado al principio, con un término que difícilmente se dejaba someter a traducción. Pero, como trataré de mostrar, no era ése el único motivo de la capacidad de la palabra para acaparar la atención. De algún modo, esa palabra hace señas. Siempre abandonada como de manera accidental, en la nota para la segunda edición de $L a$ Communauté désœuvrée ${ }^{20}$ aparece para indicar que dos de los nuevos ensayos que aumentan la primera edición se concibieron para continuar un trabajo, "por lo demás siempre en chantier, sobre la comunidad" 21 . En La Comparution, Nancy pone la palabra en circulación para aludir esta vez al pensamiento de Marx. En este texto, Nancy indica que el pensamiento de Marx no es un "pensamiento" en el mismo sentido en que lo son los de Platón, Hegel o Descartes, por ejemplo. El propio estatuto de los textos de Marx, escribe Nancy, es un indicio de lo poco que ese pensamiento se ha materializado en "obras", en "ouvres" esta vez, tal y como las entendemos habitualmente al referirnos a un autor. "Marx", entre comillas, es descrito por Nancy como "una potente máquina de agrimensura" con capacidad de "redistribuir todo el espacio común de una época" para acabar diciendo que "Marx", otra vez entre comillas, "consiste en mantener a Marx en retirada, operando desde esa retirada la salida a la luz de lo que

${ }^{18}$ J.-L. Nancy, Trafic/Déclic, op. cit., p. 17.

${ }^{19}$ Algunos de los textos citados en este artículo han sido recopilados recientemente en J.-L. Nancy, La ville au loin, París, La Phocide, 2011. Aunque este libro mantiene el título La ville au loin, que se publicó en 1999 como el volumen n 238 de una colección de Mille et Une Nuits dedicada a "La ville entière", su contenido es considerablemente más amplio puesto que aglutina los textos que Nancy le ha dedicado a la ciudad desde aquel primer texto dedicado a una de sus estancias en California (La primera parte del libro de 1999, "Au loin Los Angeles", retomaba un escrito que se publicó en 1987 en un número especial "La Ville inquiète" en Le Temps de la réflexion, Gallimard, Paris, $n^{\circ}$ VIII). Existe una traducción reciente al español: La ciudad a lo lejos, traducción de A. Sosa Varrotti, Buenos Aires, Manantial, 2013.

${ }^{20}$ J.-L. Nancy, La Communauté desœuvrée, París, Christian Bourgois, 1986 (2ª edición de 1990. Existen posteriores ediciones de 1999 y 2004).

${ }^{21}$ En una de las traducciones españolas, La comunidad desobrada, traducción de P. Perera, Arena, Madrid, 2001, la expresión se tradujo como "trabajo en ciernes", en la otra, La comunidad inoperante, traducción de J. M. Garrido, Santiago de Chile, LOM, 2000, no aparecen las notas a la segunda y tercera edición. 
queda cuando vacilan las pretensiones de volver a interpretar el mundo una vez más". Y ahora sí: lo que queda, el espacio que queda cuando ya no hay que interpretar el mundo, sino que hay que transformarlo, es, dice, "un chantier común"22 y "lo "común" como chantier", esto es, detalla, "un espacio horadado", lleno de socavones, "desordenado, ni construido ni deconstruido". Algunos años más tarde, cuando Nancy se embarca en describir la lógica o la topología de lo que ha llamado "La déclosion" 23 , y pone en circulación otro nombre para esa "compleja (y no exenta de trampas) operación" a la que Nancy se ha referido como "deconstrucción del cristianismo", esa operación también es descrita por él como un chantier à ciel ouvert. No puedo detenerme aquí en tratar de mostrar el alcance de esta declosión ni implicarme en exponer cómo lejos de limitarse a ser, como reza el subtítulo, "deconstrucción del cristianismo" (obviamente, no la deconstrucción del cristianismo puesto que cierta "adoración" 24 , por ejemplo, también es deconstrucción del cristianismo), la declosión es una operación mucho más amplia que se sirve del cristianismo como el lugar privilegiado, como el exemplum otra vez, para un nuevo pensamiento del espacio o, mejor dicho, para un nuevo pensamiento del lugar, puesto que es en una intersección del espacio y del tiempo donde el lugar puede eyectar su espaciamiento. La declosión es esta operación de espaciamiento que, en primer lugar, exige espacio para lo que de suyo está sin espacio, para lo que por definición no lo tiene: el pensamiento mismo.

Pero recuperemos el punto de partida. Lo que llamaba mi atención en las tres ocurrencias de chantier era, precisamente, que la palabra había sido como abandonada a la oportunidad de un encuentro ocasional, fortuito. La palabra había sido emplazada, tal y como ese término en castellano significa poner una cosa en determinado lugar y, a la vez, diferir una cita para más adelante. La palabra había sido emplazada entonces en un movimiento de espera que ya no sólo suponía un problema de traducción, sino que apuntaba sin hacerlas explicitas a otras cuestiones: ¿en qué podía consistir ese espacio que no está ni construido ni deconstruido? ¿Es la déclosión un sinónimo de deconstrucción? En un momento dado, y expresando la necesidad de abrir en el mundo una alteridad o una alienación incondicional, Nancy escribe que "incondicional" quiere decir "no indeconstructible" y que eso debe designar, escribe, "el alcance por derecho infinito del movimiento mismo de la deconstrucción y de la declosión". De la deconstrucción y de la declosión. "Declosión” no es sin más sinónimo de "deconstrucción". La declosión es acaso ese chantier que va a permitirnos captar ese movimiento de la deconstrucción que ningún indeconstructible detiene o, dicho de manera más elíptica, la declosión es la deconstrucción en chantier. En lo que sigue vamos a tratar de ver qué es ese "espacio" en chantier porque, como ya hemos

\footnotetext{
${ }^{22}$ J.-L. Nancy, La Comparution, París, Christian Bourgois, 1991 (2a ed. 2007), p. 73.

${ }^{23}$ J.-L. Nancy, La Déclosion (Déconstruction du christianisme, 1), op. cit., p. 23.

${ }^{24}$ J.-L. Nancy, L'Adoration (Déconstruction du christianisme, 2), Paris, Galilée, 2010.
} 
dicho, con él se nos ofrece la posibilidad de un nuevo pensamiento del lugar que nos permitirá abordar a su vez un pensamiento de la ciudad, si bien, es preciso adelantarlo ahora, la ciudad es un lugar, pero es un lugar donde tiene lugar algo diferente del lugar:

"Se trata de una metamorfosis del lugar en otra realidad que ya no pertenece al lugar, que ya no es local, sino de un orden diferente: del orden del emplazamiento y de la situación. El lugar, en efecto, procede de un cruce del espacio y del tiempo; aquí y ahora, algo tiene lugar, ha tenido lugar o tendrá lugar"25.

A partir de un texto reciente de Nancy titulado "De la struction" podemos, quizás, intentar acercarnos de manera muy sucinta a esas cuestiones. Averiguar de qué se trata con ese espacio común, ni construido ni deconstruido, porque acaso ahí estén las claves que nos ayuden a habérnoslas con nuestra habitación y con nuestra cohabitación, que nos ayuden a averiguar dónde habitaremos y cómo, y si todavía podrá tratarse de habitar cuando un día la ciudad "olvide hasta su propio nombre". Ese día, escribe Nancy:

"[...] el recuerdo de la Ciudad flotará solamente, impalpable, a través de las redes y a lo largo de los flujos de lo que ya no podremos llamar "civilización”, puesto que la propia civitas se habrá vuelto impalpable. Emplearemos otra palabra que no podemos conocer ahora pero que se parecerá más bien a un término como "almagesto" o bien será algo así como "recipiente a rebosar", a no ser que pueda llamarse "zonificación” o quizás también y simplemente "mundo".

Pero esa cosa, esa ultra-civilización que habrá excedido la ciudad no tendrá imagen: sólo la transparencia del concepto"26.

Tratando de aproximarse a las condiciones de posibilidad de ese "mundo" por venir, o de esos "multimundos", cuando ya no es seguro que podamos referirnos ni a un mundo ni a un habitar y cuando ya no podemos hacer vaticinios acerca esa civilización, de ese mundo entero en metamorfosis, en el libro titulado precisamente ¿En qué mundos vivimos?, Nancy conceptualiza lo que podríamos traducir por "estrucción" [struction]. Partiendo de la esencial imbricación de naturaleza y técnica, que en otros lugares ha tematizado con el nombre de "ecotecnia", Nancy constata que: "la técnica no le llega a la naturaleza desde un afuera. La técnica tiene su sitio en la naturaleza o, mejor aún, si la naturaleza se define como lo que culmina por sí misma sus fines, entonces también la técnica debe considerarse como un fin de la naturaleza puesto que es en la naturaleza donde nace el animal capacitado para la téc-

${ }^{25}$ J.-L. Nancy, "Images de la ville" en La Ville au loin, op. cit., p. 48.

${ }^{26}$ Ibidem, p. 47. 
nica o que tiene necesidad de ella" ${ }^{27}$. A la técnica le es aplicable asimismo el hecho de que, como la naturaleza, también culmina por sí misma sus propios fines, puesto que experimenta su propio desarrollo no respondiendo solamente a las insuficiencias naturales, sino produciendo sus propias expectativas y respondiendo a solicitudes propias e inherentes. Lo que la técnica pone así en evidencia es que, finalmente, la naturaleza también está desprovista de fines, puesto que los fines supuestamente naturales proliferan y vuelven a transformarse incesantemente en medios. Asistimos, por tanto, a la constatación de que fines y medios nunca dejan de intrincarse, de intercambiar sus papeles y que ha sido, precisamente, la técnica la que, desde finales del siglo XIX, ha venido poniendo en evidencia esta retroalimentación al tiempo que, con esta manifestación, dejaba también al descubierto su pulsión destructora. Nancy, en consecuencia, no se refiere a la técnica en el sentido en que hoy en día hablamos de "tecnologías", sino a la técnica como "estructuración de fines (un pensamiento, una cultura, una civilización, como queramos decir) de la construcción indefinida de combinaciones de fines siempre más ramificados, entrelazados y compuestos, pero sobre todo, de fines que se caracterizan por el constante despliegue de sus propias construcciones" ${ }^{28}$. Eso, según Nancy, confirma a su vez el modo en que "construcción" y "deconstrucción" interactúan, se corresponden y se pertenecen una a otra de manera muy estrecha, íntima y esencial: "lo que se construye según una lógica de fines y medios", escribe, "se deconstruye al contacto de ese límite extremo en que los fines ponen en evidencia que están sin fines y los medios, a su vez, se revelan como fines temporales en los que pueden engendrarse nuevas posibilidades de construcción"29.

Entre naturaleza y técnica se da algo así como una pulsión de construcción y destrucción que nos insta a pensar de una manera diferente la naturaleza y la técnica: "Si la "técnica" proporciona el sentido de la "naturaleza" a partir de la cual se construye y a la que destruye al mismo tiempo", ya ni siquiera es posible hablar de "naturaleza" o de "técnica". Sin embargo, fueron necesarios muchos siglos para que la aparente firme distinción establecida por Aristóteles entre physis y techné empezara a tambalearse dejando al descubierto que "“la técnica”, añadiendo fines a la naturaleza y aplicando fines que la naturaleza desconoce, construye en realidad la propia idea de esta "naturaleza" (su inmanencia, su autofinalidad, su ley de florecimiento y plenitud). Pero es también la técnica la que destruye y la que deconstruye esta idea y con ella, una estructura completa de representaciones que organizaban el pensamiento occidental"30.

\footnotetext{
${ }^{27}$ J.-L. Nancy \& A. Barrau, Dans quel monde vivons-nous? París, Galilée, 2011, p. 82.

${ }^{28}$ Ibidem, p. 82.

${ }^{29}$ Ibidem, p. 83.

${ }^{30}$ Ibidem, p. 86.
} 
Esa quiebra de la estructura representacional occidental es coextensiva con la quiebra del esquema constructivo que se había expandido con la urbanización. Si la khere de la modernidad estuvo marcada por el motivo de la destrucción, ese hecho fue también coextensivo con el crecimiento excesivo, con la excrecencia de la construcción. Así lo expone Nancy: "El paradigma constructivo que se expandió con la urbanización, los medios de transporte y de exploración y la movilización de energías", como el carbón, el gas, el petróleo o la electricidad y cuyas técnicas, como hemos visto, habían vuelto consustanciales e indiscernibles fines y medios, entraña y acarrea una reacción de destrucción". Una reacción de destrucción que va de la mano con otra destrucción con la que ya no se trató de "demolición", sino de "desprenderse de lo que se podría llamar el «constructivismo»". No se trató de demolición ni de ruina, sino de Destruktion y Abbau, tal y como más tarde esos términos heideggerianos serían traducidos por Granel y Derrida por “deconstrucción”. Hipertrofiándose, sobrepasándose y superándose a sí mismo, el propio paradigma constructivo había puesto en evidencia que la construcción está habitada desde el principio por el germen de la destrucción y de la deconstrucción. Y eso era lo que a su vez nuestra historia había podido poner en evidencia: que el paradigma constructivo no se desgastó por hiperconstrucción, sino que la "arquitectónica" y la "arquitectura" dejaron de valernos como paradigmas conceptuales porque el propio principio de la construcción estaba ya quebrado desde siempre y desde su interior por ser una construcción metafísica, ontoteológica, en cierto sentido. Es lo que el siglo XX puso en evidencia descarnadamente y sin paliativos. Por eso no puede tratarse de "volver a construir", y con una gracia infinita Nancy se refiere a la reiterativa y machacona pregunta que una vez y otra se dirige a los llamados "deconstruccionistas”: “¿acabarán ustedes por volver a construir?”31. Es, precisamente, la destrucción del paradigma constructivo moderno, que va de la mano con la quiebra del esquema representacional, lo que impide volver a construir entendiendo por esto un regreso "a los gestos fundadores, edificadores, constituyentes o instituyentes". Ahora bien, deberá tratarse, por supuesto, escribe Nancy, de "abrir y de inaugurar, de dejar nacer sentido. Lo que debe cuestionarse más allá de construcción y de destrucción es la estrucción". En lo que sigue, y en líneas muy generales, trataré de esbozar en qué consiste para Nancy dicha "estrucción", para mostrar a continuación que no consiste sino en la operación del chantier que estamos tratando de aprehender, un chantier que no es tanto un espacio como un lugar en el sentido en que antes nos referíamos a la intersección del espacio y del tiempo que permite un espaciamiento. Un chantier en cuyo espaciamiento puede tener lugar algo diferente del lugar. Una vez más, se trata de la œuvre asediada desde dentro por cierto désœuvrement, lo que, en ese sentido, nos permite también entender mejor por qué el trabajo sobre la comunidad está "por lo demás siempre en chantier".

\footnotetext{
${ }^{31}$ Ibidem, p. 89.
} 
El verbo latino struo puede traducirse por dos verbos cuyo recuerdo solicité al lector que mantuviera en la memoria al inicio de este trabajo. Struo significa "amontonar", "apiñar". Con dicho verbo se alude en latín al montón, al conjunto no ensamblado, no organizado y no ordenado. Struo hace referencia a la contigüidad y a la copresencia, pero a una contigüidad sin principio de coordinación. Dicha coordinación, escribe Nancy, pudo suponerse atribuible tanto a la naturaleza como a la técnica, pero cuando la técnica "retro-actúa" sobre la naturaleza del modo en que ya hemos visto que lo hace, "la «técnica»" confunde las dos posibilidades de coordinación, y, en consecuencia, "nos exhorta a considerar una «estrucción»", esto es, no ya una coordinación sino, una "simultaneidad no coordinada de las cosas o de los seres, la contingencia de sus copertenencias, la dispersión de las profusiones de aspectos, de especies, de fuerzas, de formas, de tensiones y de intenciones". Es la técnica, por tanto, la que nos ofrece con esta estrucción la posibilidad de una nueva ontología, (y esto da respuesta de algún modo a una cuestión que ya se planteaba sin plantearse en Las Musas: si la tecnología puede constituir una ontología o implicarla ${ }^{32}$ ), una ontología que ni siquiera llevará ese nombre, que será algo así como un conjunto ontológico desordenado y desorganizado, un conjunto ontológico que ya no es sólo el de los seres, sino también el de las cosas, una ontología que ya no será sustancial en el sentido de la fundación absoluta, sino accidental y contingente, y que ya no será sustantiva, sino "relacional". En rigor, no podría tratarse siquiera de un conjunto puesto que "con" ya no "compartiría". "Con", tal y como ha sido conceptualizado por Nancy, sólo puede ser, como ya propusiera Heidegger en el mit del mit-dasein, simple yuxtaposición sin sentido, únicamente categorial y no existencial. A partir de ahí, Nancy analiza el modo en que el paradigma arquitectural, constructivista y metafísico se transformó primero en estructural, esto es, compositivo, pero sin finalidad constructora y, más tarde, en "estruccional", es decir, "relativo a una combinación débil, desordenada, agregada o amalgamada antes que conjunta, reunida, combinada o asociada".

Con ese nuevo término, Nancy nos invita, por decirlo como Bailly, a pensar el mundo y la existencia en el "registro de la disposición" ${ }^{33}$, en el registro de la disposición de espacios y tiempos con el que pensar también nuestra propia disposición, que no consiste sino en nuestro ser-juntos, en nuestra "sociación”: “¿Puede haber asociación, sociedad; si el socius es aquel que "va con", que "acompaña" y si, en consecuencia, pone en marcha un valor activo y positivo del "con", del cum alrededor del cual o mediante el cual se cuestiona algo de un compartir? Lo que llamo aquí "estrucción" sería el estado del "con" privado del valor de compartir, desplegando únicamente la simple contigüidad con su contingencia" 34 . Lo que se nos ofrece, por

\footnotetext{
32 J.-L. Nancy, Les Muses, op. cit., p. 15.

${ }^{33}$ C. Bailly, "La Ville au-delà du lieu" en La Ville au loin, Paris, Mille et une nuits, 1999, p. 63.

${ }^{34}$ J.-L. Nancy \& A. Barrau, Dans quel monde vivons-nous?, op. cit., p. 90.
} 
tanto, con la estrucción es la pura y simple yuxtaposición y la simultaneidad de las copresencias, esto es, lo que en otros lugares Nancy ha llamado la comparecencia: "que el aparecer, es decir, la llegada al mundo y el ser en el mundo, la existencia como tal, es estrictamente inseparable del cum" "35 "Copresencia y comparecencia desvían juntas el en sí y la construcción" 36 o los estaban desviando ya desde siempre. El ser ya no es sino "contigüidad, contacto, tensión, torsión, cruce y disposición”, lo que no supone sin embargo un abandono a la pura exterioridad de partes indiferenciadas. Además de esta nueva distribución o disposición espacial, la estrucción revela una temporalidad distinta que "da acceso", escribe Nancy, "menos a un pasado y a un futuro, que a un presente no obstante jamás colmado en una presencia. Implica una temporalidad que decididamente no puede responder ya a la diacronía lineal"37. En la estrucción hay "algo sincrónico" y que no se trata de un corte o una sección en la diacronía, sino de "un modo de unidad de las partes del tiempo tradicional que es la unidad misma del presente en la medida en que se presenta, que llega, que tiene lugar, que sobreviene". Sobreviene entonces un afuera del tiempo en el corazón del tiempo y "sobrevenir es el tiempo de la estrucción: acontecimiento cuyo valor no es solo el de lo imprevisto y lo inaugural, [...] sino el del paso, la travesía, el tránsito"38.

"La estrucción libera de la obsesión que pretende pensar lo real o el ser bajo el esquema de construcción y que se agota así en la búsqueda vana de un arquitecto o un mecánico del mundo.

La estrucción ofrece un des-orden que no es lo contrario ni la ruina de un orden: se sitúa en lo que llamamos contingencia, lo fortuito, dispersión, errancia, que merece de igual modo los nombres de sorpresa, invención, ocasión, encuentro, pasaje. No se trata sino de la copresencia o, mejor, de la com-parecencia de todo lo que aparece, es decir, de lo que es" 39 .

Con estas herramientas, y a través de este paradigma estruccional y de su estrategia en chantier que ya no es ni constructiva ni deconstructiva, pero sólo porque es constructiva y deconstructiva a la vez, intentaremos acercarnos ya muy brevemente al modo en que para Nancy la problemática de la ciudad, desde el primer escrito que le dedica en 1987 a la ciudad de Los Ángeles, "Au loin, Los Angeles", no constituye una "cuestión" o un motivo de "interrogación". Con la ciudad se trata, como hemos adelantado, de una metamorfosis del lugar en otra realidad que ya no tiene que ver con el lugar, sino con la metamorfización, esto es, con el cambio, con la transformación,

\footnotetext{
${ }^{35}$ J.-L. Nancy, Etre Singulier Pluriel, París, Galilée, p. 83.

36 "De la struction" en J.-L. Nancy \& A. Barrau, Dans quel monde vivons-nous?, op. cit., p. 92.

${ }^{37}$ Ibidem, p. 95.

${ }^{38}$ Ibidem.

${ }^{39}$ Ibidem, p. 97.
} 
con aquello cuya esencia consiste en la producción constante de algo distinto, de otra cosa. Desde el principio, e incluso remontándonos a la villa antes que a la ciudad, "algo adviene: un sistema de tensiones, una relación de fuerzas y de señales que no debe ya nada directamente a las fuerzas ni a las señales de la tierra o del cielo" ${ }^{40}$. La ciudad es una metamorfosis del lugar en algo diferente que, como ya hemos adelantado, no es local, sino del "orden del emplazamiento y de la situación": "El emplazamiento procede de un cálculo abstracto: se trata de ocuparlo, de sitiarlo y de hacerle producir su espacio y su tiempo"41. Produciendo su espacio y su tiempo, la ciudad no produce sino su propio desplazamiento, siempre móvil y en metamorfosis perpetua, en ese sentido, la ciudad es una circulación, un sistema de remisiones, de correspondencias que, en primer lugar, la refieren siempre a sí. Deberemos, por tanto, pensar la ciudad para que la ciudad pueda pensarse a sí misma, para que pueda referirse a sí, para que pueda poner de manifiesto su subjetividad, una subjetividad que, como la de cualquier sujeto, cuanto más se refiere a sí para buscar su suelo y su fundamento más se extravía. "Urbanistas sin empleo" no recibimos de la ciudad sino una invitación a "deambular", ahora bien, de forma que deambular no suponga ni un concepto ni un cuestionamiento de la ciudad, sino la oportunidad de dejarle su oportunidad a la ciudad, la oportunidad de que nuestra forma de acercarnos a la ciudad entre en resonancia con esa ontología del accidente que venimos trazando, siendo la propia ciudad accidental (ya hemos visto como en chantier la ciudad no es sino un gran accidente ininterrumpido), accidental y contingente, puesto que, como lo indica Nancy en el prefacio de la última edición de La ville au loin, "La ciudad no ha existido siempre, no existirá siempre" y puede que quizás "ni siquiera exista ya". Ahora bien, eso no quiere decir que la ciudad tendría una vida que podría marchitarse hasta morir. La ciudad no es un organismo, es un cuerpo de distinta especie: un cuerpo "que no sólo remite a sí mismo y a la unidad integrada de su funcionamiento, sino que se dirige, al contrario, en todos los sentidos a la vez, hacia adentro de sí tanto como hacia afuera de sí, en un no man's land donde se confunden el interior y el exterior, el aquí y el otra parte, tu cuerpo y el mío, donde se vuelven todos indiscernibles. El cuerpo de la ciudad se trasplanta en millones de cuerpos singulares que absorbe y expulsa simultáneamente: que traga sin digerir, atravesada por gente y por cosas (trastos, mensajes, mercancías) que van a otro lugar, que hacen algo distinto que ser la vida de la ciudad"42. La ciudad no tiene vida, por tanto, sino existencia: "la ciudad se separa de la vida, de su inmediatez, de su reproducción, para ir en dirección de la existencia, de su exposición, de la lógica de la producción y de la obra". Y en la medida en que expone la existencia, la ciudad es inseparable del régimen cum y de todo lo que Nancy

\footnotetext{
${ }^{40}$ J.-L. Nancy, "Images de la ville” en La Ville au loin, op. cit., p. 48.

${ }^{41}$ Ibidem.

${ }^{42}$ J.-L. Nancy, “La ville au loin (1999)” en La Ville au loin, op. cit., p. 40.
} 
ha podido pensar infatigablemente a partir de esa partícula prepositiva que, aplicada al pensamiento de la ciudad, le ha llevado a afirmar que la ciudad es "la artista del vivir juntos": "La ciudad nace de un arte, o de una combinación de artes, cuya finalidad es precisamente producir una obra, pero una obra capaz de dar lugar a su vez a algo como un arte: a una técnica, a un saber, a una aptitud dispuestas con miras al vivir juntos. El arte de la ciudad -genitivo objetivo- es el arte de producir un arte de la ciudad -genitivo subjetivo- que vuelve a la ciudad artista -talentosa, genial, creadoraen materia del vivir juntos"43. La ciudad como sujeto de un arte (sujeto que, por una parte, se tiene a sí mismo por objeto, puesto que tenerse a sí mismo como objeto es la razón de un sujeto, aunque, por otra parte, tiene sus miras puestas fuera de sí en la producción de un vivir juntos) revela de algún modo su naturaleza poiética y práxica a la vez, "deconstruyendo" y "descentrando" lo que es y lo que hay pero afirmando al tiempo lo que todavía no es o no hay. Si la ciudad nace de un arte cuya finalidad es producir una obra capaz de dar lugar a su vez un arte, el poíema (la manufactura, la obra) producido por la poiesis (la construcción, la creación, el hacer) en el sentido de la producción del chantier ininterrumpido del ser-con, ese arte no puede revelarse sino de naturaleza eminentemente práxica, puesto que su técnica es sin finalidad, es decir, es una actividad, incluso una agitación, y su acción no se agota en la producción de objetos, sino que es un impulso o una iniciativa sin modelo y sin garantías que no tiene otro fin que ella misma y la perfección del propio agente que la ciudad es como artista, como "artista del vivir juntos".

¿Y cómo no tener la tentación de declarar que, como artista, la ciudad no ha realizado su tarea todo lo bien que hubiera sido deseable? ¿Alguna vez, como se plantea el propio Nancy en La ville au loin, la vida en la ciudad ha dejado de ser penosa, salvaje y bárbara, despiadada con los pobres, angustiante para los solitarios, agotadora para los trabajadores? Ciertamente, apenas nacida la ciudad está en espera de sí misma, en falta de sí, se preocupa por su tamaño, por su expansión, por su saturación, por las cargas de su administración, y desde que tiene conciencia de sí tiene también conciencia de los temores que despierta y de las quejas que suscita. En muchos sentidos, la accidentalidad que le venimos aplicando es catastrófica, y si todas las catástrofes no son equivalentes, sino que lo verdaderamente catastrófico es la equivalencia general que Nancy no se ha cansado de denunciar, acaso a la ciudad en general le podamos aplicar la descripción que hizo Le Corbusier de Nueva York

\footnotetext{
${ }^{43}$ J.-L. Nancy, "L'art de la ville", en Anglophonia. Frech Jornal of English Studies, Toulouse, Presses Universitaires du Mirail, $n^{\circ}$ 25/2009, p. 11.

${ }^{44}$ K. Frampton, Le Corbusier (textos de arquitectura), Madrid, Akal, 2001, p. 85. Según Le Corbusier, si bien los arquitectos habían sido capaces de grandeza en la precisión de su tarea, los urbanistas habían sido por completo unos incompetentes que no habían sido capaces de evitar y prever los embotellamientos en el constante flujo de idas y venidas entre la periferia y el centro urbano.
} 
cuando tuvo la temeridad de declarar en una conferencia de prensa ante el público americano que su ciudad era una "catástrofe mágica" 44 . La ciudad es una catástrofe mágica que deja ver la "catástrofe civilizacional que no deja de propagarse en todo momento" 45 , pero que lleva con ella las posibilidades de "producir lo contrario de una catástrofe", esto es, de revertir la equivalencia general en inequivalencia de todas las singularidades que en la ciudad se dan cita.

“Quizás otra civilización está aquí ya, entre nosotros. Lo que, sin embargo, no nos dispensa en absoluto de velar por el porvenir, de protegerlo y de dejarlo advenir, por progresión o por transformación, por irrupción o por revolución, por conminación o por afirmación, formas éstas cuya mezcla produce lo contrario de una catástrofe"46.

La obra, el arte, la invención de la ciudad tiene que perseguir un encuentro, un encuentro casual, azaroso, caótico incluso, puesto que para constituir una ciudad es preciso que el vivir juntos no sea algo dado y que haya que inventarlo a cada instante y sólo a nosotros nos toca prolongar el arte de la ciudad. Nos toca a nosotros que ya no somos "hermanos", sino "vecinos", puesto que la ciudad se ha estructurado siempre a partir de una relación no familiar, una relación de orden exterior a la unidad familiar del hogar, ajena a la domesticidad del oikos. Somos vecinos en una vecindad y de una vecindad que ante todo es contigüidad, coexistencia y copresencia distribuida en zonas de todo tipo en las que la ciudad se excede, se desplaza, se disuelve y se borra.

En el artículo cuyo título podríamos traducir por "Los dos porvenires de la ciudad"47, Nancy, implicándose en cierta prospectiva en materia de urbanismo, plantea que hay dos formas o dos formaciones que se reparten el horizonte actual de la ciudad: dos porvenires de la ciudad o su porvenir doble puesto que en ambos casos se trata de su eclipse, de su borradura o de su disolución. Una es la conurbación, ese tejido multivectorial y polinuclear, "indefinidamente extenso y distendido en redes múltiples, en buena parte inmateriales, comunicacionales, virtuales, de una actividad que se descentra hasta el punto de no permitir un punto de vista integrador y la postulación de identidad que la ciudad llevaba consigo". La otra forma de proyección, el otro porvenir, lleva en francés un nombre sarcástico y terrible: bidonville, literalmente, la ciudad-bidón, es decir, las chabolas, las favelas, los espacios marginales, periféricos, no integrados o desintegrados en los que la ciudad se disuelve y que "pronto designará el modo de vivienda de la tercera parte de la humanidad". Entre esas dos

\footnotetext{
${ }^{45}$ J.-L. Nancy, L’Équivalence des catastrophes (Après Fukushima), París, Galilée, p. 57.

${ }^{46}$ Ibidem, p. 62, nota 1.

${ }^{47}$ J.-L. Nancy, "Les deux avenirs de la ville", en N. Descendre, Le Bottin des Lumières, Nancy, Mission, 2005.
} 
formas que se reparten por turnos y a veces una contra otra o una en lo otra, "las entrañas expuestas" de la ciudad "antes "tentacular" hoy más bien molecular, reticular, estocástica", los arúspices, explica Nancy, tienen motivos para dudar largo y tendido. Quizás no podamos ver venir lo que viene y acaso no sepamos darle nombre a esa ultracivilización que viene después de la ciudad desbordada de sí misma y por sí misma excedida (ni conurbación, ni megalópolis, ni metápolis), pero lo que sí sabemos es que, sea lo que sea aquello que esté por venir, nosotros somos transeúntes sin destino, que jamás dejamos de transitar, y sabemos también que ese viaje no lo hacemos solos y que nuestro deambular será siempre, en consecuencia, coambulación. 